\title{
Pobreza y usos del tiempo de la ciudadanía guipuzcoana ${ }^{1}$
}

\section{Raquel Sanz}

SIIS Centro de Documentación y Estudios

<estudios@siis.net>

Joseba Zalakain

SIIS Centro de Documentación y Estudios

\section{Julia Nogueira}

Consultora independiente

\section{Jaione Cia}

SIIS Centro de Documentación y Estudios
Artikulu honetan, 2014ko Gipuzkoako Pobrezia eta Gizarte Bazterketari buruzko Inkestan denboraren erabilpenen inguruan egin den modulu tematikoaren oinarrizko emaitzak biltzen dira, hainbat ezaugarri soziodemografikoen arabera, 16 urte eta gehiagoko biztanleria gipuzkoarraren denboraren erabilpenak ezagutzeko helburuarekin, denbora pobreziaren kontzeptua barneratuz, eta denbora pobrezia, diru pobrezia eta gizarte-bazterketaren arteko harremana aztertuz. Jasotako datuen arabera, gipuzkoarrek 10 ordu eta 11 minutu eskaintzen dizkiote behar fisiologikoen asebetetzeari; 5 ordu eta 36 minutu bizitza sozial eta aisialdiari; eta 3 ordu eta 34 minutu lan ordainduari.

\section{GAKO-HITZAK:}

Denboraren erabilerak, generoa, pobrezia, denbora pobrezia, Gipuzkoa.
Este artículo sintetiza los resultados del módulo sobre usos del tiempo realizado dentro de la Encuesta de Pobreza y Exclusión Social de Gipuzkoa de 2014. El objetivo del estudio es conocer los usos del tiempo de la población guipuzcoana de 16 y más años en función de diversas características sociodemográficas, introducir el concepto de pobreza de tiempo y analizar la relación que existe entre ésta, la pobreza monetaria y la exclusión social. Según los datos recogidos, entre el 16,8 \% y el $25,8 \%$ de la población guipuzcoana es pobre en tiempo, según se considere como indicador disponer de menos de 12 horas diarias para satisfacer las necesidades fisiológicas y de tiempo libre, 0 tener menos de 3 horas diarias de tiempo libre. La incidencia de la pobreza de tiempo es mayor entre las mujeres, quienes trabajan a jornada completa, quienes conviven con personas dependientes y, en especial, entre quienes tienen entre 30 y 44 años.

\section{Palabras Clave:}

Usos del tiempo, género, pobreza, pobreza de tiempo, Gipuzkoa. 


\section{Introducción: objetivos y metodología}

Este artículo sintetiza los resultados de un informe sobre usos del tiempo elaborado por el SIIS Centro de Documentación y Estudios a partir de la Encuesta de Pobreza y Exclusión Social de Gipuzkoa de 2014. El análisis se ha llevado a cabo a propuesta de la Dirección de Igualdad de la Diputación Foral de Gipuzkoa, y persigue conocer las diferencias sociodemográficas que existen -particularmente desde el punto de vista del género- en el tiempo que se dedica a las diferentes tareas y actividades que conforman una jornada ordinaria. Como objetivos específicos, el estudio se plantea:

- Describir y examinar los usos del tiempo de la población guipuzcoana de 16 y más años en función de las principales variables sociodemográficas.

- Introducir el concepto de pobreza de tiempo y conocer su incidencia en nuestro territorio, así como las características sociodemográficas de aquellas personas en mayor medida afectadas por este fenómeno.

- Analizar la relación existente entre la pobreza de tiempo y la pobreza monetaria o la exclusión social.

El análisis se deriva de una batería específica de preguntas introducida en el cuestionario de la mencionada encuesta ${ }^{2}$ en relación con el tiempo que dedican las personas entrevistadas y los miembros de su unidad familiar (en horas y minutos) a siete actividades concretas, diferenciando entre los días laborables y los fines de semana y festivos. Las actividades incluidas son las necesidades fisiológicas, el trabajo remunerado, la formación, el trabajo doméstico no remunerado, los cuidados no remunerados a otras personas en el hogar o la familia, la vida social y ocio, y los trayectos. La elección de estas actividades se basa en la que utiliza Eustat en la Encuesta de Presupuestos del Tiempo ${ }^{3}$, que se encuentra, a su vez, armonizada con la lista de actividades elaborada por Eurostat ${ }^{4}$. Evidentemente, en la medida en que la división social del trabajo constituye un determinante fundamental de la vida cotidiana, las actividades asociadas al trabajo ocupan un papel muy significativo en esta selección de grandes grupos de actividades. En este sentido, es preciso recalcar que si bien "en

${ }^{2}$ La información sobre la muestra utilizada en la Encuesta de Pobreza y Exclusión Social de Gipuzkoa de 2014 se recoge en detalle en el informe de resultados (SIIS Centro de Documentación y Estudios, 2015b). En todo caso, cabe señalar que se encuestó a un total de 1.507 hogares de todo el territorio, y que la encuesta tiene un margen de error, para intervalos de confianza del $95 \%$ y máxima varianza $(p=q)$, de $\pm 2,52 \%$ para el conjunto de la muestra.

3 En el caso de la Encuesta de Presupuestos de Tiempo, Eustat diferencia, entre los grandes grupos de actividades personales de la vida cotidiana, el ocio activo y el ocio pasivo, que en el caso de este estudio se han incorporado a la variable 'vida social y ocio', por una cuestión de síntesis, ya que se considera que agrupar dichas categorías no supone una pérdida de información relevante respecto a los objetivos planteados en el estudio.

4 Para más información, puede consultarse la Harmonised European Time Use Survey (〈https://www.h5.scb.se/tus/tus/〉). la sociedad actual se ha dado prioridad al trabajo remunerado, cuyo tiempo tiene un precio de mercado, sobre los otros tipos de trabajo [...], el tiempo dedicado al trabajo remunerado no se entiende sin el tiempo de trabajo doméstico, sin el sustento de las actividades relacionadas con la denominada reproducción de la fuerza de trabajo, o también cuidado de la vida y que comprende tanto tareas domésticas como cuidados a personas integrantes del hogar" (Eustat, 2003).

Este análisis sobre el uso del tiempo ha tenido como elemento central las desigualdades de género, "ya que [el género] se construye en base a adscripciones culturales, y es el que imprime las diferencias más considerables en el empleo del tiempo, especialmente en aquellas actividades básicas sobre las que se asienta y se construye el orden social establecido, como son las relacionadas con el trabajo, remunerado y no remunerado, y con el tiempo libre" (Eustat, 2006). Así, y como se ha señalado previamente, el sexo será la variable de desagregación básica que constituirá el eje central del estudio, de manera que todas las características independientes estarán también vinculadas a las diferencias en los patrones de uso del tiempo masculinas y femeninas.

\section{Los usos del tiempo de la población guipuzcoana}

La organización de las diferentes responsabilidades diarias y la satisfacción de necesidades de distinto tipo obligan a las personas a distribuir la jornada diaria en diferentes 'tiempos'. De esta manera, los estudios sobre los usos del tiempo y el diseño de las políticas públicas destinadas a su conciliación hablan de tres tiempos fundamentales en los que se agrupan diferentes actividades: tiempo de trabajo remunerado, tiempo de trabajo no remunerado y tiempo personal, en el que entraría también el tiempo destinado a la satisfacción de las necesidades fisiológicas (comer, dormir, asearse). Si bien en algunos casos estos grupos de actividades se solapan, y si bien los límites entre ellos no siempre se pueden establecer con total claridad, es evidente que esta distinción resulta la más útil y la más operativa para analizar las diferencias en los patrones de uso del tiempo por parte de la población adulta.

Partiendo de esta premisa, se han seleccionado tres indicadores para analizar qué proporción de la jornada destina por término la población, o un grupo determinado, a una tarea concreta, cuántas personas participan en esa actividad y durante cuánto tiempo.

- Tiempo medio social: es el tiempo medio que dedica el conjunto de la población, o un grupo determinado, a una actividad dada, teniendo en cuenta para el cálculo de los valores promedio tanto a quienes realizan esa actividad como a quienes no la realizan. 
- Tasa de participación: es la proporción de la población, o de un grupo determinado, que realiza una actividad dada.

- Tiempo medio por participante: es el tiempo promedio que destinan a cada tarea o actividad las personas que participan efectivamente en cada una de las actividades descritas.

A continuación se analizarán estos tres indicadores según las principales características sociodemográficas (sexo, edad, nacionalidad, estilo de vida y tamaño municipal) y otras variables consideradas de interés para el análisis de los usos del tiempo (ocupación, presencia de personas dependientes en el hogar, ayuda a domicilio y situación económica).

\subsection{Articulación de la jornada según características sociodemográficas básicas}

La Tabla 1 recoge los datos básicos relativos a la distribución del tiempo de la población guipuzcoana de 16 y más años en un día o jornada ordinaria en función del sexo. Según estos datos, por término medio, la población guipuzcoana dedica 10 horas y 11 minutos a la satisfacción de las necesidades fisiológicas, 5 horas y 36 minutos a la vida social y el ocio, y 3 horas y 34 minutos al trabajo remunerado. El resto de las actividades tienen una dedicación menor, destinándose, por ejemplo, prácticamente una hora al día (1:01) a los cuidados a otras personas. Desde el punto de vista de la tasa de participación, el 48,6\% de la población dedica parte de su tiempo al trabajo remunerado, el $14 \%$ a la formación y el $83,8 \%$ al trabajo doméstico. Casi el $34 \%$ realiza actividades de cuidado de otras personas, mientras que el $2,7 \%$ no participa en actividades de ocio o de carácter social. Finalmente, si se tiene en cuenta el tiempo medio por participante (es decir, el tiempo dedicado por las personas que desarrollan esas actividades), el trabajo remunerado representa, por término medio, 7 horas y 20 minutos; los trayectos, algo más de una hora (1:06); el trabajo doméstico, dos horas y media; y los cuidados a otras personas, algo más de tres horas.

Tabla 1. Tiempos medios y tasa de participación en actividades de la vida diaria durante un día promedio laborable. Población de 16 y más años, en función del sexo. Gipuzkoa, 2014

\begin{tabular}{|c|c|c|c|c|}
\hline & Hombres & Mujeres & Total & $\begin{array}{c}\text { Diferencia } \\
\text { mujeres-hombres }\end{array}$ \\
\hline \multicolumn{5}{|l|}{ Tiempo medio social } \\
\hline Trabajo remunerado & $4: 14$ & 2:57 & $3: 34$ & $-01: 17$ \\
\hline Formación & $0: 42$ & $0: 38$ & $0: 40$ & $-00: 04$ \\
\hline Trayectos & $0: 53$ & $0: 46$ & $0: 49$ & $-00: 07$ \\
\hline Trabajo doméstico no remunerado & $1: 27$ & $2: 41$ & $2: 06$ & $+01: 14$ \\
\hline Cuidados a otras personas & $0: 48$ & 1:14 & 1:01 & $+00: 26$ \\
\hline Vida social y ocio & $5: 47$ & $5: 27$ & $5: 36$ & $-00: 20$ \\
\hline Necesidades fisiológicas & 10:06 & $10: 14$ & $10: 11$ & $+00: 08$ \\
\hline \multicolumn{5}{|l|}{ Tasa de participación (\%) } \\
\hline Trabajo remunerado & 52,8 & 44,8 & 48,6 & $-7,3$ \\
\hline Formación & 14,7 & 13,4 & 14,0 & $-1,6$ \\
\hline Trayectos & 76,5 & 72,3 & 74,4 & $-4,1$ \\
\hline Trabajo doméstico no remunerado & 75,6 & 91,5 & 83,8 & $+17,6$ \\
\hline Cuidados a otras personas & 30,6 & 37,0 & 33,9 & $+7,0$ \\
\hline Vida social y ocio & 98,2 & 96,6 & 97,3 & $-1,8$ \\
\hline Necesidades fisiológicas & 100,0 & 100,0 & 100,0 & $+0,0$ \\
\hline \multicolumn{5}{|l|}{ Tiempo medio participante } \\
\hline Trabajo remunerado & $8: 02$ & $6: 35$ & $7: 20$ & $-01: 27$ \\
\hline Formación & $4: 47$ & $4: 45$ & $4: 46$ & $-00: 02$ \\
\hline Trayectos & $1: 09$ & $1: 04$ & $1: 06$ & $-00: 05$ \\
\hline Trabajo doméstico no remunerado & $1: 56$ & $2: 56$ & $2: 30$ & $+01: 00$ \\
\hline Cuidados a otras personas & $2: 37$ & $3: 20$ & $3: 02$ & $+00: 43$ \\
\hline Vida social y ocio & $5: 53$ & $5: 38$ & $5: 45$ & $-00: 15$ \\
\hline Necesidades fisiológicas & 10:06 & $10: 14$ & 10:11 & $+00: 08$ \\
\hline
\end{tabular}

Fuente: SIIS Centro de Documentación y Estudios (2015a). 
A priori, puede decirse que la distribución del tiempo sigue los condicionamientos clásicos de la división de roles de género, ya que mientras que los hombres dedican más tiempo al trabajo remunerado, ellas lo hacen al trabajo doméstico, siendo las diferencias prácticamente simétricas (algo más de una hora y cuarto a favor de los hombres en lo que se refiere al trabajo remunerado, y el mismo tiempo a favor de las mujeres en lo que se refiere al trabajo doméstico). A ello hay que hay que sumar diferencias, también a favor de las mujeres -aunque algo menos relevantes, 26 minutos- en su dedicación al cuidado a otras personas. Las mujeres tomadas en conjunto tienen menos tiempo libre y dedican, como resultado de estas diferencias, 20 minutos menos al día que los hombres a las actividades sociales y de ocio.

En lo que se refiere a las tasas de participación, el porcentaje de hombres que participan en actividades laborales remuneradas es mayor, y el de quienes participan en actividades de trabajo doméstico o cuidados a otras personas es menor. En el caso del trabajo doméstico no remunerado, las diferencias son bastante significativas, ya que ellas cuentan con una tasa de participación 17 puntos más alta que en el caso de los hombres ( $75 \%$ frente a $91 \%$ ). Por otro lado, existen diferencias, aunque menos significativas, relacionadas con el trabajo de cuidado a otras personas, para el que la proporción es 7 puntos mayor en el caso de las mujeres (30\% frente a $37 \%$ ).

Teniendo en cuenta el tiempo medio social dedicado a cada una de las actividades en función del sexo, la tendencia es la misma y las diferencias se mantienen, dedicando las mujeres ocupadas en el mercado laboral casi una hora y media menos al trabajo remunerado que los hombres, una hora diaria más a actividades de trabajo doméstico, y tres cuartos de hora más al cuidado de otras personas. Las diferencias son menores si se atiende al resto de actividades, como la formación, los trayectos, la vida social y las necesidades fisiológicas. Así pues, las mujeres no sólo se dedican en mayor proporción que los hombres al trabajo doméstico y a los cuidados, sino que, cuando lo hacen, le dedican más tiempo que los hombres.

Aparte de la influencia del género, el efecto de la trayectoria vital puede apreciarse con claridad en lo tocante a la dedicación a un empleo remunerado, de manera que el grupo etario más joven (16 a 29 años) se encuentra en una transición entre formación

Tabla 2. Tiempos medios y tasa de participación en actividades de la vida diaria durante un día promedio laborable. Población de 16 y más años, en función de la edad. Gipuzkoa, 2014

\begin{tabular}{|c|c|c|c|c|c|}
\hline & 16-29 años & 30-44 años & 45-64 años & 65 y más años & Total \\
\hline \multicolumn{6}{|l|}{ Tiempo medio social } \\
\hline Trabajo remunerado & $2: 26$ & $5: 35$ & $5: 04$ & $0: 06$ & $3: 34$ \\
\hline Formación & $3: 38$ & $0: 15$ & $0: 07$ & $0: 02$ & $0: 40$ \\
\hline Trayectos & $0: 59$ & $0: 51$ & $0: 52$ & $0: 38$ & $0: 49$ \\
\hline Trabajo doméstico no remunerado & $0: 59$ & 1:58 & $2: 20$ & 2:34 & 2:06 \\
\hline Cuidados a otras personas & $0: 31$ & $1: 50$ & $0: 49$ & $0: 43$ & $1: 01$ \\
\hline Vida social y ocio & $5: 10$ & $3: 46$ & $4: 53$ & $8: 46$ & $5: 36$ \\
\hline Necesidades fisiológicas & $10: 15$ & $9: 41$ & $9: 51$ & $11: 06$ & $10: 11$ \\
\hline \multicolumn{6}{|l|}{ Tasa de participación } \\
\hline Trabajo remunerado & 37,4 & 75,9 & 67,3 & 1,5 & 48,6 \\
\hline Formación & 56,0 & 8,8 & 7,5 & 3,0 & 14,0 \\
\hline Trayectos & 87,1 & 81,8 & 78,0 & 54,0 & 74,4 \\
\hline Trabajo doméstico no remunerado & 68,7 & 88,3 & 87,2 & 83,6 & 83,8 \\
\hline Cuidados a otras personas & 15,9 & 55,7 & 31,5 & 24,6 & 33,9 \\
\hline Vida social y ocio & 99,3 & 94,7 & 97,2 & 99,2 & 97,3 \\
\hline Necesidades fisiológicas & 100,0 & 100,0 & 100,0 & 100,0 & 100,0 \\
\hline \multicolumn{6}{|l|}{ Tiempo medio por participante } \\
\hline Trabajo remunerado & $6: 31$ & $7: 22$ & $7: 31$ & $7: 22$ & $7: 20$ \\
\hline Formación & $6: 29$ & 2:55 & $1: 40$ & $1: 35$ & $4: 46$ \\
\hline Trayectos & $1: 07$ & $1: 02$ & $1: 07$ & $1: 11$ & 1:06 \\
\hline Trabajo doméstico no remunerado & $1: 26$ & $2: 14$ & $2: 41$ & $3: 05$ & $2: 30$ \\
\hline Cuidados a otras personas & $3: 15$ & $3: 18$ & $2: 38$ & $2: 57$ & $3: 02$ \\
\hline Vida social y ocio & $5: 12$ & $3: 59$ & 5:02 & $8: 51$ & $5: 45$ \\
\hline Necesidades fisiológicas & $10: 15$ & $9: 41$ & $9: 51$ & $11: 06$ & $10: 11$ \\
\hline
\end{tabular}

Fuente: SIIS Centro de Documentación y Estudios (2015a). 
y empleo, y por tanto, dedica menos tiempo a este último que las personas de entre 30 y 64 años, que se encuentran en plena edad productiva. También reflejan los ciclos vitales los resultados extraídos a partir de la dedicación horaria a las tareas domésticas no remuneradas, que aumenta en función de la edad. Las personas con menos cargas remuneradas y de cuidado invierten más en tiempo personal, tendencia cristalizada en el comportamiento de las personas que superan los 64 años y que, habiendo abandonado el mercado laboral y con menores cargas familiares, son las que más tiempo dedican a la vida social y al ocio.

Las tasas de participación en las diversas tareas reflejan también las diferencias relacionadas con el ciclo vital, ya que la población más joven es la que cuenta con el porcentaje de participación más alto en actividades formativas, y, por el contrario, más bajo en trabajo doméstico no remunerado y cuidados a otras personas. Por otro lado, la población de entre 30 y 44 años es la que en mayor medida está orientada al trabajo remunerado, con una tasa muy superior a la del resto de edades, y también des- taca por una tasa muy elevada de dedicación a las actividades de cuidados a otras personas, debido a que tiende a concentrarse en este tramo de edad la tenencia y crianza de los hijos e hijas. En cuanto al tiempo medio por participante, las diferencias de dedicación horaria se suavizan, tal y como puede verse en la Tabla 2.

La nacionalidad es otro aspecto que se ha de tener en cuenta a la hora de analizar los usos del tiempo. A pesar de las diferencias en las tasas de ocupación de las personas extranjeras 5 y españolas, el tiempo medio dedicado al trabajo remunerado y no remunerado es muy similar en ambos grupos (Tabla 3 ). Las diferencias se centran en el tiempo de formación y desplazamiento, mayor en el caso de las personas extranjeras, lo cual se traduce en que los espacios dedicados a la vida social y a las necesidades fisiológicas son más cortos para las personas de nacionalidad extranjera. Estas diferencias se hacen algo más patentes si se observa la participación de un grupo y otro en actividades formativas y en deslazamientos, aunque las diferencias son escasas en lo que se refiere a la tasa de participación en el resto de

Tabla 3. Tiempos medios y tasa de participación en actividades de la vida diaria durante un día promedio laborable. Población de 16 y más años, en función de la nacionalidad. Gipuzkoa, 2014

\begin{tabular}{|c|c|c|c|}
\hline & \\
\hline & Española & Extranjera & Total \\
\hline \multicolumn{4}{|l|}{ Tiempo medio social } \\
\hline Trabajo remunerado & $3: 33$ & $3: 44$ & $3: 34$ \\
\hline Formación & $0: 37$ & $1: 19$ & $0: 40$ \\
\hline Trayectos & $0: 48$ & $1: 01$ & $0: 49$ \\
\hline Trabajo doméstico no remunerado & 2:06 & 2:06 & $2: 06$ \\
\hline Cuidados a otras personas & $1: 01$ & $1: 08$ & $1: 01$ \\
\hline Vida social y ocio & $5: 40$ & $4: 50$ & $5: 36$ \\
\hline Necesidades fisiológicas & $10: 12$ & $9: 49$ & $10: 11$ \\
\hline \multicolumn{4}{|l|}{ Tasa de participación } \\
\hline Trabajo remunerado & 48,7 & 47,5 & 48,6 \\
\hline Formación & 13,3 & 23,3 & 14,0 \\
\hline Trayectos & 74,1 & 78,3 & 74,4 \\
\hline Trabajo doméstico no remunerado & 84,1 & 80,4 & 83,8 \\
\hline Cuidados a otras personas & 34,0 & 33,2 & 33,9 \\
\hline Vida social y ocio & 97,4 & 96,4 & 97,3 \\
\hline Necesidades fisiológicas & 100,0 & 100,0 & 100,0 \\
\hline \multicolumn{4}{|l|}{ Tiempo medio por participante } \\
\hline Trabajo remunerado & $7: 18$ & $7: 51$ & $7: 20$ \\
\hline Formación & $4: 38$ & $5: 41$ & $4: 46$ \\
\hline Trayectos & $1: 05$ & $1: 17$ & 1:06 \\
\hline Trabajo doméstico no remunerado & $2: 29$ & $2: 37$ & 2:30 \\
\hline Cuidados a otras personas & 3:00 & $3: 26$ & $3: 02$ \\
\hline Vida social y ocio & $5: 49$ & $5: 01$ & $5: 45$ \\
\hline Necesidades fisiológicas & $10: 12$ & $9: 49$ & $10: 11$ \\
\hline
\end{tabular}

Fuente: SIIS Centro de Documentación y Estudios (2015a). 
actividades. Por tanto, se observa que las personas extranjeras no sólo participan en mayor medida en actividades de formación, sino que, cuando lo hacen, le dedican más tiempo; lo mismo ocurre con el trabajo remunerado -media hora más al día de trabajo, por término medio-, los trayectos (quizá por residir más lejos de los centros de trabajo y formación) y los cuidados a otras personas; por el contrario, dedican menos tiempo al ocio y a la vida social.

Cuando los usos del tiempo se analizan en función del hábitat de residencia -medido a través del tamaño del municipio en el que se reside-, se observan diferencias importantes, que derivan en estilos de vida diferentes, al menos si se tiene en cuenta el tiempo dedicado a la vida social y al ocio (Tabla 4). Mientras que no existen diferencias muy reseñables en el tiempo dedicado a actividades de trabajo remunerado ni de formación, sí parecen existir en cuanto al tiempo dedicado al resto de actividades señaladas. Por una parte, el tiempo medio dedicado a los trayectos es algo mayor en los municipios pequeños (de menos de 10.000 habitantes). Las diferencias más notables se relacionan, en cualquier caso, con la situación de quienes viven en municipios de más de 50.000 habitantes -es decir, Irun y Donostia-, puesto que no sólo dedican menos tiempo por término medio a los trayectos, sino también al trabajo doméstico y a los cuidados a otras personas; por el contrario, dedican mucho más tiempo a la vida social y al ocio.

En lo que se refiere al porcentaje de personas que participan en cada actividad en cada uno de los tres tipos de hábitats residenciales, cabe destacar la menor tasa de participación en el cuidado a otras personas en los municipios grandes y la mayor tasa de dedicación al empleo remunerado en los pequeños. Ello coincide con sus mayores tasas de ocupación y sus menores tasas de paro. Si se limita la comparación del tiempo destinado a cada actividad únicamente a aquellas personas que realmente se dedican a ellas, se confirman las tendencias apuntadas anteriormente. La dedicación media al trabajo remunerado es parecida, también a la formación, pero el tiempo dedicado a realizar trayectos es algo mayor en los municipios pequeños. En los municipios grandes, sin embargo, no sólo participan menos personas en el trabajo doméstico y en los cuidados a terceras personas, sino que quienes participan lo

Tabla 4. Tiempos medios y tasa de participación en actividades de la vida diaria durante un día promedio laborable. Población de 16 y más años, en función del tamaño del municipio de residencia. Gipuzkoa, 2014

\begin{tabular}{|c|c|c|c|c|}
\hline & \\
\hline & <10.000 habitantes & 10.001-50.000 habitantes & > 50.000 habitantes & Total \\
\hline \multicolumn{5}{|l|}{ Tiempo medio social } \\
\hline Trabajo remunerado & $3: 58$ & 3:16 & $3: 42$ & $3: 34$ \\
\hline Formación & $0: 35$ & $0: 40$ & $0: 42$ & $0: 40$ \\
\hline Trayectos & 1:00 & $0: 51$ & $0: 41$ & $0: 49$ \\
\hline Trabajo doméstico no remunerado & 2:14 & $2: 26$ & 1:36 & 2:06 \\
\hline Cuidados a otras personas & 1:12 & 1:14 & $0: 41$ & 1:01 \\
\hline Vida social y ocio & $4: 48$ & $5: 13$ & $6: 31$ & $5: 36$ \\
\hline Necesidades fisiológicas & 10:09 & $10: 16$ & 10:05 & 10:11 \\
\hline \multicolumn{5}{|l|}{ Tasa de participación } \\
\hline Trabajo remunerado & 54,8 & 45,6 & 48,7 & 48,6 \\
\hline Formación & 12,3 & 14,9 & 13,9 & 14,0 \\
\hline Trayectos & 75,0 & 75,7 & 72,4 & 74,4 \\
\hline Trabajo doméstico no remunerado & 84,9 & 85,9 & 80,7 & 83,8 \\
\hline Cuidados a otras personas & 38,3 & 39,1 & 25,2 & 33,9 \\
\hline Vida social y ocio & 96,7 & 96,5 & 98,7 & 97,3 \\
\hline Necesidades fisiológicas & 100,0 & 100,0 & 100,0 & 100,0 \\
\hline \multicolumn{5}{|l|}{ Tiempo medio por participante } \\
\hline Trabajo remunerado & $7: 14$ & $7: 10$ & $7: 36$ & $7: 20$ \\
\hline Formación & 4:47 & 4:33 & 5:01 & $4: 46$ \\
\hline Trayectos & 1:20 & 1:07 & $0: 56$ & 1:06 \\
\hline Trabajo doméstico no remunerado & $2: 38$ & $2: 50$ & 2:00 & 2:30 \\
\hline Cuidados a otras personas & $3: 08$ & 3:09 & $2: 42$ & 3:02 \\
\hline Vida social y ocio & $4: 58$ & $5: 25$ & $6: 36$ & $5: 45$ \\
\hline Necesidades fisiológicas & 10:09 & $10: 16$ & 10:05 & $10: 11$ \\
\hline
\end{tabular}

Fuente: SIIS Centro de Documentación y Estudios (2015a). 
hacen durante menos tiempo. Todo ello conduce a una mayor dedicación de tiempo a la vida social y al ocio en las ciudades de más de 50.000 habitantes. En el caso de los municipios pequeños, el mayor tiempo dedicado a los trayectos, al trabajo doméstico y al trabajo de cuidados trae aparejado una dedicación mucho menor a las actividades de ocio y a la vida social.

Los datos desagregados por estas tres características sociodemográficas básicas (edad, nacionalidad y tamaño de municipio) pueden analizarse, al mismo tiempo, en función del sexo. Las mayores diferencias en lo que se refiere al tiempo medio de mujeres y hombres dedican a las distintas actividades se producen en la etapa que va de los 30 a los 44 años: las mujeres trabajan en empleos remunerados algo más de una hora y media menos que los hombres y destinan 43 minutos menos al ocio y la vida social, mientras que dedican 1 hora y 14 minutos más al trabajo doméstico y una hora más a los cuidados a otras personas.

Las diferencias entre géneros, aunque existen, son en general menores en los otros grupos de edad. En todo caso, es importante señalar que la dedicación media a las labores domésticas es muy diferente entre hombres y mujeres en todos los tramos de edad, salvo entre los más jóvenes, donde esa diferencia es de sólo media hora. A medida que aumenta la edad de las personas, las tasas de participación femeninas en el trabajo remunerado pierden peso en favor de las masculinas, sin afectar este cambio a su mayor peso en las labores no remuneradas, de cuidado del hogar y de otras personas.

Por otro lado, las diferencias de género en cuanto a las tasas de participación en las distintas tareas varían en función de la nacionalidad de las personas. Mientras que, en el caso de la población extranjera, las mujeres participan algo más que los hombres en el trabajo remunerado, en el caso de las personas no extranjeras es al revés. A la hora de analizar los usos del tiempo en función de la nacionalidad y el sexo de las personas, destaca básicamente un hecho: si entre los hombres y las mujeres no extranjeras las diferencias en lo que se refiere a la vida social y de ocio son reducidas (11 minutos), entre los hombres y las mujeres extranjeras la diferencia es sustancialmente mayor (casi una hora).

Tabla 5. Diferencia entre mujeres y hombres con respecto a los tiempos medios y la tasa de participación en las actividades de la vida diaria durante un día promedio laborable. Población de 16 y más años, en función de la edad. Gipuzkoa, 2014

\begin{tabular}{|c|c|c|c|c|c|}
\hline & & & & & \\
\hline & 16-29 años & 30-44 años & 45-64 años & 65 y más años & Total \\
\hline \multicolumn{6}{|l|}{ Tiempo medio social } \\
\hline Trabajo remunerado & $-00: 14$ & $-01: 35$ & $-01: 29$ & $-00: 08$ & $-01: 17$ \\
\hline Formación & $-00: 02$ & $-00: 02$ & $+00: 02$ & $+00: 01$ & $-00: 04$ \\
\hline Trayectos & $+00: 02$ & $-00: 04$ & $-00: 08$ & $-00: 10$ & $-00: 07$ \\
\hline Trabajo doméstico no remunerado & $+00: 28$ & $+01: 14$ & $+01: 24$ & $+01: 19$ & $+01: 14$ \\
\hline Cuidados a otras personas & $+00: 38$ & $+01: 02$ & $+00: 17$ & $+00: 00$ & $+00: 26$ \\
\hline Vida social y ocio & $-00: 34$ & $-00: 43$ & $-00: 17$ & $-01: 02$ & $-00: 20$ \\
\hline Necesidades fisiológicas & $-00: 17$ & $+00: 08$ & $+00: 09$ & $+00: 00$ & $+00: 08$ \\
\hline \multicolumn{6}{|l|}{ Tasa de participación } \\
\hline Trabajo remunerado & $+5,5$ & $-7,4$ & $-6,6$ & $-1,9$ & $-8,0$ \\
\hline Formación & $-2,0$ & $-0,8$ & $+0,6$ & $+0,9$ & $-1,3$ \\
\hline Trayectos & $-5,4$ & $+0,6$ & $-1,4$ & $-4,9$ & $-4,2$ \\
\hline Trabajo doméstico no remunerado & $+12,7$ & $+16,6$ & $+16,6$ & $+16,1$ & $+15,9$ \\
\hline Cuidados a otras personas & $+14,1$ & $+13,8$ & $+4,9$ & $-0,3$ & $+6,4$ \\
\hline Vida social y ocio & $-0,1$ & $-4,2$ & $-1,5$ & $-0,6$ & $-1,6$ \\
\hline Necesidades fisiológicas & $+0,0$ & $+0,0$ & $+0,0$ & $+0,0$ & $+0,0$ \\
\hline \multicolumn{6}{|l|}{ Tiempo medio por participante } \\
\hline Trabajo remunerado & $-01: 37$ & $-01: 22$ & $-01: 28$ & $+00: 22$ & $-01: 27$ \\
\hline Formación & $+00: 10$ & $+00: 01$ & $+00: 22$ & $+00: 01$ & $-00: 02$ \\
\hline Trayectos & $+00: 07$ & $-00: 05$ & $-00: 08$ & $-00: 13$ & $-00: 05$ \\
\hline Trabajo doméstico no remunerado & $+00: 24$ & $+00: 58$ & $+01: 07$ & $+01: 01$ & $+01: 00$ \\
\hline Cuidados a otras personas & $+01: 23$ & $+01: 02$ & $+00: 30$ & $+00: 03$ & $+00: 43$ \\
\hline Vida social y ocio & $-00: 34$ & $-00: 36$ & $-00: 12$ & $-00: 59$ & $-00: 15$ \\
\hline Necesidades fisiológicas & $-00: 17$ & $+00: 08$ & $+00: 09$ & $+00: 00$ & $+00: 08$ \\
\hline
\end{tabular}

Fuente: SIIS Centro de Documentación y Estudios (2015a). 
Por último, las mayores diferencias de dedicación horaria al trabajo doméstico entre hombres y mujeres ( $a$ favor de los primeros) se encuentran en los municipios más pequeños, reduciéndose relativamente a medida que aumenta el tamaño poblacional; lo mismo sucede en el caso del tiempo dedicado a los trayectos. En el caso del cuidado a otras personas, las diferencias entre hombres y mujeres -no muy acusadas- son similares en los tres tipos de municipios. Por el contrario, es en los municipios más grandes donde la diferencia entre hombres y mujeres es más abultada en lo tocante al tiempo dedicado a la vida social y el ocio. En relación con el trabajo doméstico no remunerado, las diferencias -a favor de las mujeres- se hacen más patentes en las localidades de mayor tamaño. Si se tiene en cuenta sólo a las personas que dedican algo de tiempo a cada una de las actividades identificadas, las diferencias se hacen más pequeñas, aunque siguen la misma tendencia en cuanto a la mayor dedicación masculina al trabajo remunerado, y femenina al trabajo doméstico y de cuidado a otras personas.

Las Tablas 5, 6 y 7 resumen estas diferencias de género en función de la edad, la nacionalidad y el tamaño de municipio, respectivamente, teniendo en cuenta los indicadores que ayudan a analizar con mayor precisión la presencia y participación de la población guipuzcoana de 16 y más años en cada una de las actividades incluidas en la distribución de un día ordinario.

Tabla 6. Diferencia entre mujeres y hombres con respecto a los tiempos medios y la tasa de participación en las actividades de la vida diaria durante un día promedio laborable. Población de 16 y más años, en función de la nacionalidad. Gipuzkoa, 2014

\begin{tabular}{|c|c|c|c|}
\hline & Española & Extranjera & Total \\
\hline \multicolumn{4}{|l|}{ Tiempo medio social } \\
\hline Trabajo remunerado & $-01: 21$ & $-00: 27$ & $-01: 17$ \\
\hline Formación & $-00: 02$ & $-00: 36$ & $-00: 04$ \\
\hline Trayectos & $-00: 07$ & $-00: 04$ & $-00: 07$ \\
\hline Trabajo doméstico no remunerado & $+01: 13$ & $+01: 23$ & $+01: 14$ \\
\hline Cuidados a otras personas & $+\infty: 25$ & $+00: 40$ & $+00: 26$ \\
\hline Vida social y ocio & $-00: 16$ & $-01: 02$ & $-00: 20$ \\
\hline Necesidades fisiológicas & $+00: 08$ & $+\infty: 07$ & $+00: 08$ \\
\hline \multicolumn{4}{|l|}{ Tasa de participación } \\
\hline Trabajo remunerado & $-8,8$ & $+3,5$ & $-8,0$ \\
\hline Formación & $-0,8$ & $-9,7$ & $-1,2$ \\
\hline Trayectos & $-4,2$ & $-5,5$ & $-4,2$ \\
\hline Trabajo doméstico no remunerado & $+15,6$ & $+20,7$ & $+15,9$ \\
\hline Cuidados a otras personas & $+5,5$ & $+18,7$ & $+6,4$ \\
\hline Vida social y ocio & $-1,6$ & $-1,8$ & $-1,6$ \\
\hline Necesidades fisiológicas & $+0,0$ & $+0,0$ & $+0,0$ \\
\hline \multicolumn{4}{|l|}{ Tiempo medio por participante } \\
\hline Trabajo remunerado & $-01: 28$ & $-01: 33$ & $-01: 27$ \\
\hline Formación & $+\infty: 01$ & $-00: 13$ & $-00: 02$ \\
\hline Trayectos & $-00: 06$ & $+00: 00$ & $-00: 05$ \\
\hline Trabajo doméstico no remunerado & $+01: 00$ & $+01: 06$ & $+01: 00$ \\
\hline Cuidados a otras personas & $+00: 45$ & $+00: 06$ & $+00: 43$ \\
\hline Vida social y ocio & $-00: 11$ & $-00: 58$ & $-00: 15$ \\
\hline Necesidades fisiológicas & $+00: 08$ & $+00: 07$ & $+00: 08$ \\
\hline
\end{tabular}

Fuente: SIIS Centro de Documentación y Estudios (2015a). 
Tabla 7. Diferencia entre mujeres y hombres con respecto a los tiempos medios y la tasa de participación en las actividades de la vida diaria durante un día promedio laborable. Población de 16 y más años, en función del tamaño del municipio de residencia. Gipuzkoa, 2014

\begin{tabular}{|c|c|c|c|c|}
\hline & \\
\hline & <10.000 habitantes & 10.001-50.000 habitantes & > 50.000 habitantes & Total \\
\hline \multicolumn{5}{|l|}{ Tiempo medio social } \\
\hline Trabajo remunerado & $-01: 45$ & $-01: 24$ & $-00: 53$ & $-01: 17$ \\
\hline Formación & $+00: 02$ & $-00: 07$ & $-00: 05$ & $-00: 04$ \\
\hline Trayectos & $-00: 11$ & $-00: 08$ & $-00: 02$ & $-00: 07$ \\
\hline Trabajo doméstico no remunerado & $+01: 29$ & $+01: 19$ & $+01: 02$ & $+01: 14$ \\
\hline Cuidados a otras personas & $+\infty: 21$ & $+\infty: 34$ & $+00: 22$ & $+00: 26$ \\
\hline Vida social y ocio & $-00: 06$ & $-00: 23$ & $-00: 30$ & $-00: 20$ \\
\hline Necesidades fisiológicas & $+\infty: 10$ & $+\infty: 10$ & $+00: 05$ & $+00: 08$ \\
\hline \multicolumn{5}{|l|}{ Tasa de participación } \\
\hline Trabajo remunerado & $-12,7$ & $-9,0$ & $-4,0$ & $-8,0$ \\
\hline Formación & $+0,3$ & $-2,5$ & $-0,7$ & $-1,3$ \\
\hline Trayectos & $-2,6$ & $-5,1$ & $-3,9$ & $-4,2$ \\
\hline Trabajo doméstico no remunerado & $+15,1$ & $+13,3$ & $+19,7$ & $+15,9$ \\
\hline Cuidados a otras personas & $+6,4$ & $+5,8$ & $+8,0$ & $+6,4$ \\
\hline Vida social y ocio & $-0,5$ & $-2,2$ & $-1,7$ & $-1,6$ \\
\hline Necesidades fisiológicas & $+0,0$ & $+0,0$ & $+0,0$ & $+0,0$ \\
\hline \multicolumn{5}{|l|}{ Tiempo medio por participante } \\
\hline Trabajo remunerado & $-01: 33$ & $-01: 41$ & $-01: 12$ & $-01: 27$ \\
\hline Formación & $+00: 12$ & $+00: 05$ & $-00: 20$ & $-00: 02$ \\
\hline Trayectos & $-00: 12$ & $-00: 05$ & $-00: 01$ & $-00: 05$ \\
\hline Trabajo doméstico no remunerado & $+01: 18$ & $+01: 06$ & $+\infty 0: 51$ & $+01: 00$ \\
\hline Cuidados a otras personas & $+00: 24$ & $+00: 58$ & $+00: 39$ & $+00: 43$ \\
\hline Vida social y ocio & $-00: 04$ & $-00: 17$ & $-00: 23$ & $-00: 15$ \\
\hline Necesidades fisiológicas & $+\infty: 10$ & $+\infty: 10$ & $+00: 05$ & $+00: 08$ \\
\hline
\end{tabular}

Fuente: SIIS Centro de Documentación y Estudios (2015a).

\subsection{Otros condicionantes de los usos del tiempo}

Junto con las características sociodemográficas básicas ya analizadas, se han escogido otras variables consideradas de interés para el análisis de los usos del tiempo: la ocupación laboral, la presencia de personas dependientes en los hogares, la percepción de ayuda en el domicilio para la realización de tareas domésticas y de cuidado a otras personas, y la situación económica de los hogares ${ }^{6}$.

Desde el punto de vista de su relación con la actividad, las diferencias entre los diferentes grupos (personas ocupadas a jornada completa, ocupadas a jornada parcial, paradas e inactivas) en cuanto al uso del tiempo están lógicamente marcadas, en este caso, por la presencia en el mercado laboral, de manera que el tiempo dedicado a actividades no remuneradas aumenta cuando las personas se encuentran a jornada parcial, en situación de desempleo o inactivas. Como consecuencia de

${ }^{6}$ Por motivos de espacio, las tablas referentes a la ocupación, las personas dependientes, la ayuda domiciliaria y la situación económica no se han incluido en este artículo, pero están disponibles en el informe del SIIS Centro de Documentación y Estudios (2015). estas responsabilidades, las personas ocupadas a jornada completa presentan una menor dedicación al trabajo doméstico, a los cuidados y a la vida social. Las personas paradas, por su parte, se asemejan a las inactivas en casi todos los aspectos, salvo en el tiempo dedicado a la formación y los cuidados a otras personas (algo mayor en el caso de las primeras).

En la estructuración de la jornada diaria, el trabajo familiar y doméstico -el trabajo reproductivorepresenta una obligación más y mantiene un carácter condicionante con respecto al resto de las actividades diarias. Como es lógico, la dedicación a esas tareas es distinta en función de la existencia o no en el hogar de personas dependientes, bien debido a su edad, bien a la existencia de limitaciones para el desarrollo de las actividades de la vida diaria. Cuando hay personas dependientes, la dedicación al trabajo de cuidados es mayor, todo lo cual se traduce en una disponibilidad de tiempo libre (para la vida social y el ocio) mucho menor. También cabe destacar que un $22,4 \%$ de las personas que no residen en hogares con otras personas dependientes dedican parte de su tiempo al cuidado de personas dependientes, lógicamente residentes en otros hogares. 
En este mismo sentido, otro condicionante que influye en la organización de la jornada diaria es la percepción de ayuda externa al hogar -tanto profesional como no profesional- para la realización de tareas domésticas o de cuidados a las personas. Los hogares con ayuda doméstica se diferencian de los demás en que dedican menos tiempo al trabajo remunerado, y más tiempo a la vida social y el ocio. Fundamentalmente, quienes no reciben ayuda de ningún tipo destinan más tiempo al trabajo remunerado y al trabajo doméstico.

Por último, cabe analizar en qué medida las familias que viven por encima y por debajo del umbral de pobreza relativa (hogares con unos ingresos netos inferiores al $60 \%$ de la renta mediana equivalente) tienen patrones de uso del tiempo diferentes. En la medida en que la pobreza se relaciona básicamente con la participación en el mercado laboral, la dedicación media de las personas que viven en situación de pobreza al trabajo remunerado es menor, y mayor la que le dedican a la formación. Aunque las personas en situación de pobreza relativa que trabajan dedican al empleo remunerado menos tiempo que las personas no pobres que trabajan, las personas pobres dedican más tiempo que las no pobres a los trayectos y a la formación, cuando se comparan con personas no pobres que también realizan esas tareas. Además, dedican bastante más tiempo al cuidado a otras personas, y a la vida social y al ocio.

\section{La pobreza de tiempo en Gipuzkoa}

El indicador que mide la pobreza de tiempo se centra en la participación de las personas en actividades englobadas en la categoría de vida social y ocio, actividades que cabe equiparar al tiempo libre o de descanso, y cuya duración está, por tanto, condicionada a la intensidad de los demás tiempos vitales, relacionados con el trabajo remunerado y no remunerado. Para la medición de la pobreza de tiempo y su contribución a la calidad de vida de las personas, se han escogido dos indicadores, uno de carácter relativo y otro de carácter objetivo. Aunque se basan en fórmulas de cálculo diferentes y se vinculan a formas diferentes de entender la pobreza, ofrecen unas conclusiones similares con respecto a la pobreza de tiempo y sus consecuencias entre la población guipuzcoana.

\subsection{Indicador relativo de pobreza de tiempo}

El indicador relativo de pobreza de tiempo relaciona el tiempo libre de cada persona con el tiempo libre del conjunto de la sociedad y considera pobres en tiempo a quienes tienen mucho menos tiempo libre que sus conciudadanos. Así, siguiendo a Burchardt (2008), se encuentran en situación de pobreza de tiempo aquellas personas que durante un día promedio laborable dedican a actividades relacionadas con la vida social y el ocio menos del $60 \%$ del tiempo mediano dedicado por el conjunto de la población de 16 y más años. El umbral se sitúa -para los días labo- rables y para el conjunto de la población guipuzcoana mayor de 16 años- en tres horas diarias.

Según los resultados obtenidos, un $25,8 \%$ de la población guipuzcoana mayor de 16 años está afectada por la pobreza de tiempo (es decir, cuenta con menos de 3 horas para las actividades de ocio y vida social). Pero como sucede en el análisis de los usos del tiempo, determinadas características sociodemográficas influyen también en la pobreza de tiempo.

Los datos de la Tabla 8 indican que las tasas de pobreza de tiempo son significativamente más altas entre las personas de 30 a 44 años, ya que se encuentran en plena edad activa y también es más frecuente en este rango de edad la tenencia y crianza de hijos e hijas menores con necesidad de cuidados. Con respecto al tamaño del municipio de residencia, también puede decirse que las personas que viven en localidades más pequeñas sufren en mayor medida la pobreza de tiempo. Este efecto está relacionado, probablemente, con el tiempo dedicado a los trayectos, mayor entre las personas residentes en este tipo de municipios. Por el contrario, las tasas de pobreza de tiempo son similares para hombres y mujeres $(24,8 \%$ y $26,8 \%$ ) cuando se consideran en su conjunto; $\sin$ embargo, las diferencias, a favor de los hombres, resultan algo mayores entre las personas jóvenes (hasta 44 años). Los resultados obtenidos apuntan en este sentido a una brecha intergénero de pobreza de tiempo especialmente elevada entre las personas de 30 a 44 años (el $52,2 \%$ de las mujeres de esta edad están en situación de pobreza de tiempo, frente a un $42,7 \%$ de los hombres).

Desde la perspectiva de la ocupación y la presencia de personas dependientes, se vuelve a señalar la importancia de la pobreza de tiempo femenina, de manera que entre las mujeres ocupadas a jornada completa y entre las que tienen personas dependientes a cargo, la tasa de pobreza de tiempo es mayor que la de los hombres en la misma situación.

\subsection{Indicador objetivo de pobreza de tiempo}

El enfoque del indicador objetivo de pobreza de tiempo implica aceptar que no sólo el tiempo de trabajo remunerado otorga riqueza a los hogares, ya que "la importancia del uso del tiempo se deriva del hecho de que el bienestar de un individuo no depende sólo de su ingreso o su consumo, sino de su libertad sustantiva para usar el tiempo" (Gammage, 2009). De acuerdo con este estándar de medición, se encuentran en situación de pobreza de tiempo todas aquellas personas que durante un día promedio laborable dedican más de 12 horas a actividades relacionadas con el trabajo. Independientemente de la fijación del umbral en 12 horas, cabe señalar también que, mientras que el indicador relativo se refiere a las personas que tienen poco tiempo libre, el indicador objetivo se relaciona con las personas que tienen mucho trabajo y, en general, con los grupos en los que está más presente el fenómeno de la doble jornada. 
Tabla 8. Proporción y número de personas de 16 y más años en situación de pobreza relativa de tiempo, según diversas características sociodemográficas. Gipuzkoa, 2014

\begin{tabular}{|c|c|c|c|c|c|}
\hline & & \multirow[b]{2}{*}{ Tasa (\%) } & \multicolumn{2}{|c|}{ Distribución vertical (\%) } & \multirow[b]{2}{*}{$\begin{array}{c}\text { № de personas } \\
\text { afectadas }\end{array}$} \\
\hline & & & $\begin{array}{l}\text { Personas } \\
\text { afectadas }\end{array}$ & $\begin{array}{c}\text { Total de } \\
\text { personas de } \\
16 \text { y más años }\end{array}$ & \\
\hline \multicolumn{6}{|l|}{ Hombres } \\
\hline \multirow{4}{*}{ Edad* } & $16-29$ años & 14,3 & 4,2 & 7,7 & 6.332 \\
\hline & 30-44 años & 42,7 & 22,6 & 13,6 & 33.769 \\
\hline & 45-64 años & 28,5 & 18,1 & 16,4 & 27.091 \\
\hline & 65 y más años & 3,0 & 1,2 & 10,4 & 1.815 \\
\hline \multirow{2}{*}{ Nacionalidad } & Española & 24,6 & 42,9 & 45,0 & 64.255 \\
\hline & Extranjera & 26,8 & 3,2 & 3,1 & $4 \cdot 752$ \\
\hline \multirow{3}{*}{ Tamaño del municipio* } & $<10.000$ habitantes & 32,4 & 12,9 & 10,3 & 19.296 \\
\hline & 10.001-50.000 habitantes & 27,3 & 22,2 & 21,0 & 33.265 \\
\hline & $>50.000$ habitantes & 16,9 & 11,0 & 16,8 & 16.446 \\
\hline Total hombres & & 24,8 & 46,1 & 48,1 & 69.007 \\
\hline \multicolumn{6}{|l|}{ Mujeres } \\
\hline \multirow{4}{*}{ Edad* $^{\star}$} & 16-29 años & 20,1 & 5,7 & 7,4 & 8.587 \\
\hline & 30-44 años & 52,2 & 26,5 & 13,1 & 39.652 \\
\hline & 45-64 años & 30,6 & 19,8 & 16,7 & 29.647 \\
\hline & 65 y más años & 3,3 & 1,9 & 14,7 & 2.770 \\
\hline \multirow{2}{*}{ Nacionalidad } & Española & 26,3 & 48,7 & 47,8 & 72.836 \\
\hline & Extranjera & 32,6 & 5,2 & 4,1 & 7.820 \\
\hline \multirow{3}{*}{$\begin{array}{l}\text { Tamaño del municipio de } \\
\text { residencia* }\end{array}$} & $<10.000$ habitantes & 30,9 & 12,6 & 10,5 & 18.850 \\
\hline & $10.001-50.000$ habitantes & 31,0 & 26,4 & 22,0 & 39.502 \\
\hline & $>50.000$ habitantes & 19,8 & 14,9 & 19,4 & 22.304 \\
\hline Total mujeres & & 26,8 & 53,9 & 51,9 & 80.656 \\
\hline \multicolumn{6}{|l|}{ Total } \\
\hline \multirow{4}{*}{ Edad* $^{*}$} & 16-29 años & 17,1 & 10,0 & 15,0 & 14.919 \\
\hline & 30-44 años & 47,4 & 49,1 & 26,8 & 73.421 \\
\hline & 45-64 años & 29,5 & 37,9 & 33,2 & 56.738 \\
\hline & 65 y más años & 3,2 & 3,1 & 25,1 & 4.584 \\
\hline \multirow{2}{*}{ Nacionalidad } & Española & 25,5 & 91,6 & 92,8 & 137.091 \\
\hline & Extranjera & 30,2 & 8,4 & 7,2 & 12.572 \\
\hline \multirow{3}{*}{ Tamaño del municipio* } & $<10.000$ habitantes & 31,6 & 25,5 & 20,8 & 38.146 \\
\hline & 10.001-50.000 habitantes & 29,2 & 48,6 & 43,0 & 72.766 \\
\hline & $>50.000$ habitantes & 18,5 & 25,9 & 36,2 & 38.750 \\
\hline \multicolumn{2}{|l|}{ Total } & 25,8 & 100,0 & 100,0 & 149.662 \\
\hline
\end{tabular}

* Diferencias estadísticamente significativas de acuerdo con la prueba $\chi^{2}$ para $p<0,05$ Fuente: SIIS Centro de Documentación y Estudios (2015a). 
Tabla 9. Proporción y número de personas de 16 y más años en situación de pobreza objetiva de tiempo, según diversas características sociodemográficas. Gipuzkoa, 2014

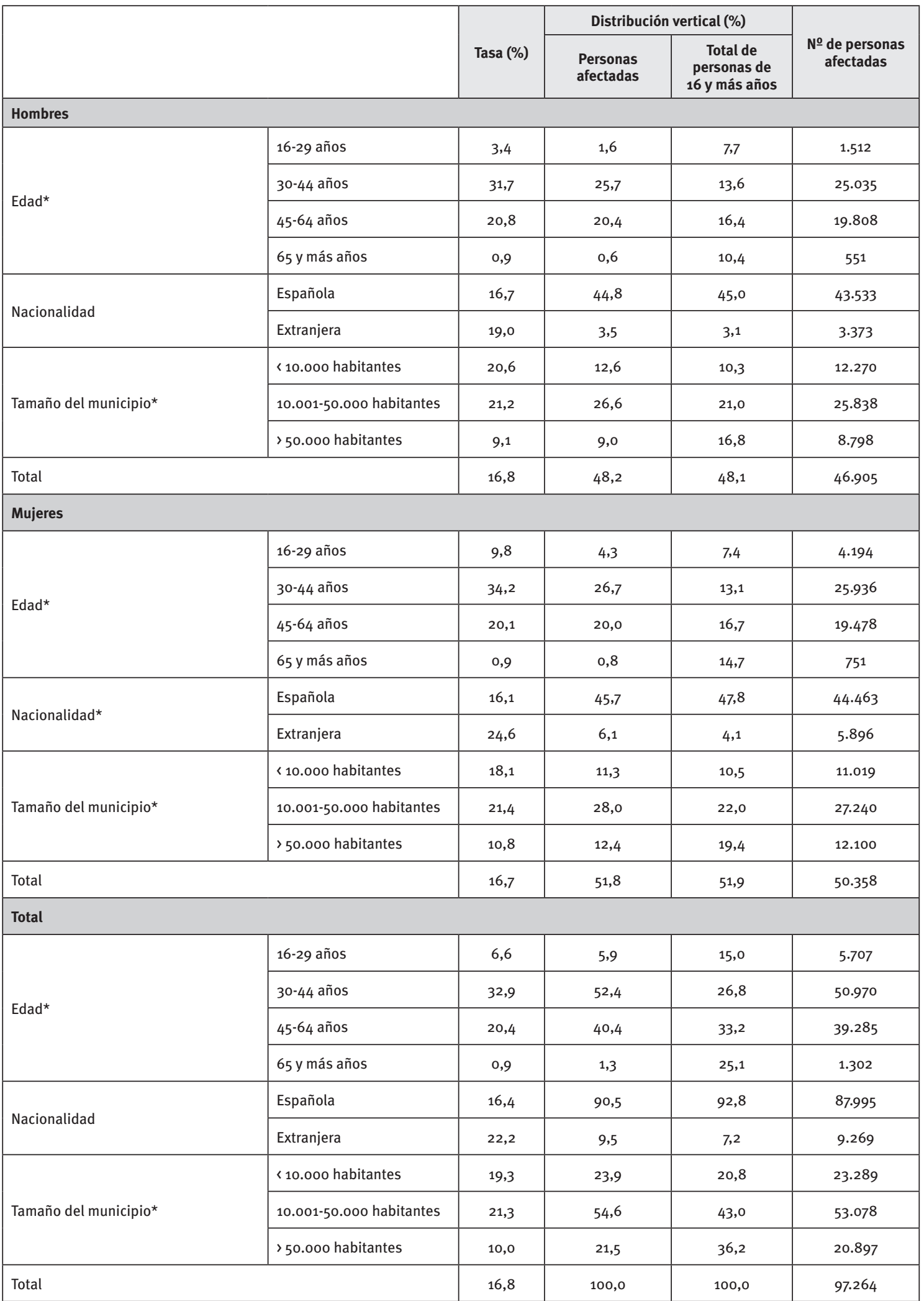

* Diferencias estadísticamente significativas de acuerdo con la prueba $\chi^{2}$ para $p<0,05$

Fuente: SIIS Centro de Documentación y Estudios (2015a). 
Según los datos mostrados en la Tabla 9, la edad y el tamaño de municipio de residencia son factores que determinan con mayor claridad el riesgo de padecer pobreza objetiva de tiempo. Entre el conjunto de la población, un tercio de las personas de 30 a 44 años están en esta situación, frente a menos del $1 \%$ entre la población de 65 años y más. Con respecto a las diferencias entre hombres y mujeres, es importante señalar que las mujeres jóvenes (16-29 años) padecen en mayor medida situaciones de pobreza de tiempo que los hombres de este mismo rango de edad.

Desde el punto de vista de la ocupación, existen tasas más altas de personas que dedican más de 12 horas a tareas 'obligatorias' entre las personas ocupadas a jornada completa. También son más altas entre las personas que viven en hogares con personas dependientes, especialmente en aquellos que reciben ayuda para la realización de esos cuidados, el $37 \%$ de los cuales se encuentran en esa situación.

\section{Relación entre pobreza de tiempo, pobreza monetaria y exclusión social}

Antes de profundizar en la relación entre pobreza de tiempo, pobreza monetaria y exclusión social, pueden resultar ilustrativos los datos que se proporcionan en Gráfico 1, en el que se ofrece el tiempo medio que destinan a actividades relacionadas con la vida social y el ocio distintos grupos poblacionales, agrupados por quintiles según sus ingresos equivalentes. Tal y como puede observarse, nivel de ingresos y tiempo libre disponible presentan en este caso una relación inversamente proporcional, en la medida en que un aumento en el nivel de ingresos implica una disminución del tiempo libre disponible.

Efectivamente, los resultados del Gráfico 1 ponen de manifiesto que el $20 \%$ de la población con unos ingresos equivalentes más reducidos (primer quintil) dispone por término medio de 1 hora y 42 minutos diarios más de tiempo para actividades de ocio y relaciones sociales que el $20 \%$ de aquellas que disponen de unos ingresos más elevados (último quintil). Asimismo, atendiendo a la distribución de estos parámetros en función del sexo, es preciso destacar que, en todos los casos, las mujeres cuentan con un tiempo disponible para estas actividades menor que el de los hombres, siendo especialmente elevada la brecha existente en el primer quintil de ingresos, donde la diferencia, a favor de los hombres, es de 1 hora y 7 minutos más de tiempo libre.

Gráfico 1. Distribución de la población de 16 y más años en función del sexo, por quintiles de ingresos equivalentes (euros/mes) y tiempo medio social durante un día promedio laborable destinado a las actividades de vida social y ocio. Gipuzkoa, 2014

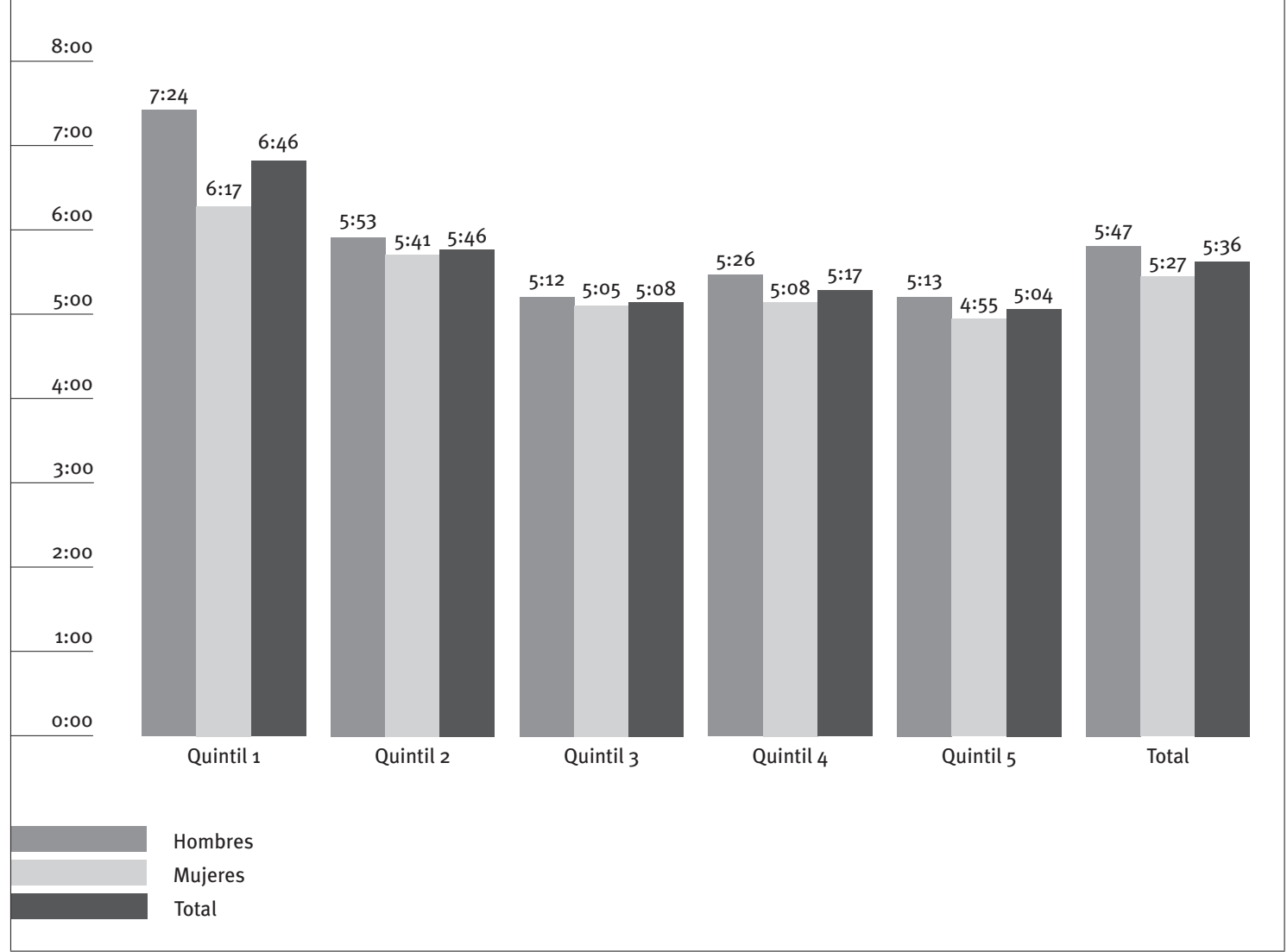

Fuente: SIIS Centro de Documentación y Estudios (2015a). 

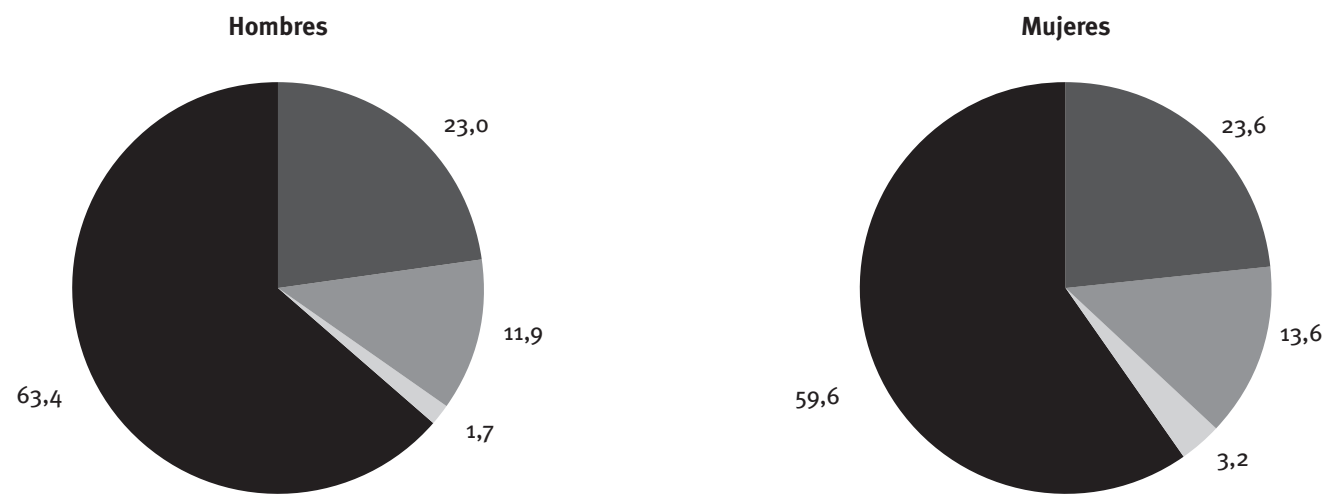

Sólo pobreza de tiempo

Sólo pobreza monetaria

Ambas

Ninguna

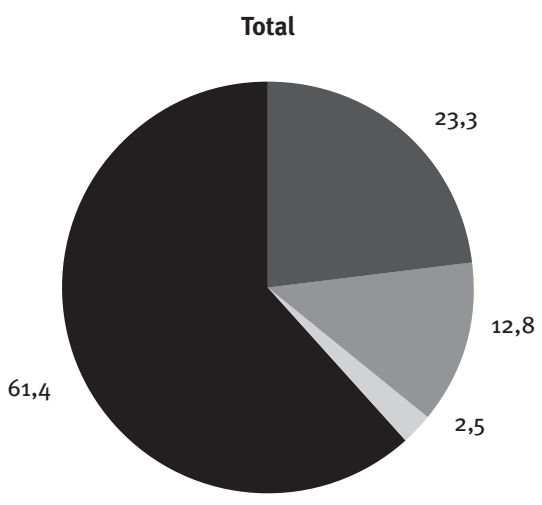

Fuente: SIIS Centro de Documentación y Estudios (2015a).

En cuanto a la distribución entre la población general de 16 y más años de las situaciones de pobreza de tiempo ${ }^{7}$ y pobreza monetaria (Gráfico 2), cabe destacar, en primer lugar, que el $61,4 \%$ de la población no se encuentra afectada por ninguna de las dos contingencias. En cambio, el 38,6\% de la población sufre alguna de estas dos situaciones, ya sea pobreza de tiempo $(23,3 \%)$ o monetaria (12,8\%) de manera exclusiva, ya sean las dos (2,5\%). Cabe señalar además que, si bien las diferencias no son excesivamente elevadas, en el caso de las mujeres la proporción de quienes sufren algún tipo de pobreza es mayor (el 40,4\%, frente al 36,6\% de los hombres) y que la proporción de mujeres que experimentan ambos tipos de pobreza (el $3,2 \%)$ duplica la de los hombres (1,7\%).

Tal y como puede comprobarse en la Tabla 10, es muy similar si en lugar de considerar el indicador relativo de pobreza se toma como referencia el indicador

7 Como se explicaba anteriormente, este indicador se calcula a partir del umbral del $60 \%$ de la mediana del tiempo dedicado por el conjunto de la población guipuzcoana de 16 y más años a actividades relacionadas con la vida social y el ocio. Concretamente, este umbral se sitúa en 3 horas diarias, considerándose así pobres aquellas personas con una disponibilidad de tiempo libre menor. objetivo de pobreza de tiempo, aquel que identifica a las personas pobres en tiempo en función de la dedicación en más de 12 horas diarias a actividades relacionadas con el trabajo.

Los resultados de la Tabla 10 sugieren que si bien el solapamiento de ambos fenómenos (pobreza monetaria y pobreza de tiempo) es minoritario, su asociación e interdependencia resultan obvias: aquellas personas que se encuentran en situación de pobreza relativa tienen tasas menores de pobreza de tiempo que las que no se encuentran en esta situación (el $11,9 \%$ frente al $17,7 \%$ ); en cambio, entre las personas pobres en tiempo, la tasa de pobreza monetaria es ciertamente menor que la de aquellas que, por diversos motivos, pueden disponer de mayor tiempo libre (el 10,8\%, frente al 16,2\%).

Por otro lado, la pobreza de tiempo también se compara con la exclusión social, indicador que implica otros factores, además de los económicos, como el acceso a recursos relacionados con la salud, la vivienda, la educación o las relaciones sociales.

A diferencia de lo observado en cuanto a la pobreza relativa, la asociación entre las situaciones de exclusión social y la pobreza de tiempo, ya sea a través 
Tabla 10. Distribución de las personas de 16 y más años en función de su situación con respecto a la pobreza de tiempo (indicador objetivo) y la pobreza monetaria. Gipuzkoa, 2014 (\% verticales)

\begin{tabular}{|c|c|c|c|c|}
\hline & & \multicolumn{3}{|c|}{ Pobreza relativa } \\
\hline & & Presencia & Ausencia & Total \\
\hline \multirow{3}{*}{ Hombres } & Presencia & 11,0 & 17,8 & 16,8 \\
\hline & Ausencia & 89,0 & 82,2 & 83,2 \\
\hline & Total & 100,0 & 100,0 & 100,0 \\
\hline \multirow{3}{*}{ Mujeres } & Presencia & 12,6 & 17,6 & 16,7 \\
\hline & Ausencia & 87,4 & 82,4 & 83,3 \\
\hline & Total & 100,0 & 100,0 & 100,0 \\
\hline \multirow{3}{*}{ Total } & Presencia & 11,9 & 17,7 & 16,8 \\
\hline & Ausencia & 88,1 & 82,3 & 83,2 \\
\hline & Total & 100,0 & 100,0 & 100,0 \\
\hline
\end{tabular}

Fuente: SIIS Centro de Documentación y Estudios (2015a).

Tabla 11. Distribución de las personas de 16 y más años en función de su situación con respecto a la pobreza de tiempo (indicador relativo y objetivo) y la exclusión social. Gipuzkoa, 2014 (\% sobre el total de cada subtabla)

\begin{tabular}{|c|c|c|c|c|}
\hline & & \multicolumn{3}{|c|}{ Exclusión social } \\
\hline & & Presencia & Ausencia & Total \\
\hline \multicolumn{5}{|c|}{ Indicador relativo } \\
\hline \multirow{3}{*}{ Hombres } & Presencia & 2,4 & 22,4 & 24,8 \\
\hline & Ausencia & 11,0 & 64,2 & 75,2 \\
\hline & Total & 13,3 & 86,7 & 100,0 \\
\hline \multirow{3}{*}{ Mujeres } & Presencia & 3,0 & 23,8 & 26,8 \\
\hline & Ausencia & 10,8 & 62,4 & 73,2 \\
\hline & Total & 13,8 & 86,2 & 100,0 \\
\hline \multirow{3}{*}{ Total } & Presencia & 2,7 & 23,1 & 25,8 \\
\hline & Ausencia & 10,9 & 63,3 & 74,2 \\
\hline & Total & 13,6 & 86,4 & 100,0 \\
\hline \multicolumn{5}{|c|}{ Indicador objetivo } \\
\hline \multirow{3}{*}{ Hombres } & Presencia & 1,8 & 15,0 & 16,8 \\
\hline & Ausencia & 11,5 & 71,6 & 83,2 \\
\hline & Total & 13,3 & 86,7 & 100,0 \\
\hline \multirow{3}{*}{ Mujeres } & Presencia & 2,0 & 14,7 & 16,7 \\
\hline & Ausencia & 11,8 & 71,5 & 83,3 \\
\hline & Total & 13,8 & 86,2 & 100,0 \\
\hline \multirow{3}{*}{ Total } & Presencia & 1,9 & 14,9 & 16,8 \\
\hline & Ausencia & 11,7 & 71,5 & 83,2 \\
\hline & Total & 13,6 & 86,4 & 100,0 \\
\hline
\end{tabular}

Fuente: SIIS Centro de Documentación y Estudios (2015a).

del indicador relativo o del objetivo, no resulta en términos generales estadísticamente significativa. Con todo, el comportamiento de ambas variables es muy similar al observado en el caso de la pobreza monetaria. De este modo, la Tabla 11 muestra que entre las personas que se encuentran en situación de exclusión social, la incidencia de la pobreza de tiempo, ya sea con uno $u$ otro indicador, resulta algo menor que entre las personas situadas en un espacio social de integración. También es muy reducida la proporción de quienes sufren ambos tipos de contingencia (el 2,7 \% de la población en el caso del indicador relativo de pobreza de tiempo y el 1,9\% en el del indicador objetivo), así como las diferencias entre hombres y mujeres. 


\section{Conclusiones}

En primer lugar, el informe sintetizado en este artículo analiza la dedicación horaria al trabajo remunerado, al trabajo doméstico y de cuidados, a la formación, a los trayectos, a la vida social y al ocio, y a las necesidades fisiológicas de la población en función de un conjunto de variables independientes relacionadas con diversas características sociodemográficas básicas. Éstos han sido los principales resultados obtenidos en el análisis de los usos del tiempo:

- El estudio confirma la persistencia de los roles tradicionales de género en lo que se refiere a los usos del tiempo, ya que los hombres dedican más tiempo al trabajo remunerado ( 4 horas y14 minutos, frente a 2 horas y 57 minutos en el caso de las mujeres), y las mujeres, más tiempo al trabajo doméstico y el cuidados de otras personas (3 horas y 55 minutos, frente a 2 horas y 15 minutos en el caso de los hombres).

- Aunque la variable de género ha constituido el eje de análisis de este estudio, el componente generacional resulta tanto o más relevante. Cabe destacar la situación de las personas en edad reproductiva y laboral (30-44 años), con una menor disponibilidad para el tiempo libre y el ocio, debido a su mayor dedicación al trabajo remunerado y a los cuidados a otras personas. La población de 30 a 44 años dedica por término medio 1 hora y 46 minutos a actividades relacionadas con la vida social y el ocio, es decir, 1 hora y 24 minutos menos que las personas de 16 a 29 años, y 5 horas menos que las personas de $65 \mathrm{y}$ más años.

- Si se analizan las diferencias en el uso del tiempo de la población en función de la nacionalidad, hay que señalar que el tiempo medio por participante de las personas extranjeras es significativamente mayor, tanto en el caso del trabajo remunerado, como en el caso de las tareas domésticas y los cuidados a otras personas. Cuando se cruzan las variables de sexo y nacionalidad, se observa que las diferencias de género no son muy abultadas en el caso del tiempo destinado a la vida social por parte de la población no extranjera (las mujeres destinan 16 minutos menos que los hombres). En cambio, en el caso de las mujeres extranjeras, esa diferencia es de 1 hora y 2 minutos en relación a los hombres de nacionalidad extranjera, debido a su mayor dedicación a las tareas domésticas y de cuidados a otras personas.

- Según los diferentes estilos de vida acordes al tamaño del municipio de residencia, las personas que viven en municipios de más de 50.000 habitantes (Donostia e Irun) dedican menos tiempo a los trayectos, al cuidado de otras personas y al trabajo doméstico, y más tiempo al ocio y a la vida social.
En segundo lugar, este trabajo define el concepto de pobreza de tiempo y su relación con la pobreza económica y la exclusión social a partir de los datos recogidos sobre los usos del tiempo de la población guipuzcoana. El análisis de tales datos arroja las siguientes conclusiones:

- Entre un $16,8 \%$ y un $25,8 \%$ de la población guipuzcoana es pobre en tiempo. El 25,8\% de la población guipuzcoana está afectada por la pobreza de tiempo, ya que su disponibilidad horaria para el tiempo libre es menor de 3 horas. Si se utiliza un indicador más restrictivo, el porcentaje de población que dispone de menos de 12 horas diarias para satisfacer sus necesidades fisiológicas y de tiempo libre, la tasa sería del $16,8 \%$. Sólo en el caso del primer indicador (indicador relativo) se observan diferencias significativas entre hombres y mujeres en cuanto a la incidencia de la pobreza de tiempo.

- Más allá del género, las principales diferencias sociodemográficas en cuanto a la pobreza de tiempo se relacionan con la edad: mientras que para las personas de 30 a 44 años el indicador de pobreza relativa alcanza el 42,7\% -es decir, casi de la mitad de las personas de esas edades son pobres en tiempo-, en el caso de las personas mayores de 65 años el porcentaje es del $3 \%$. Nuevamente, y pese a que en todos los tramos de edad la incidencia de este problema es mayor entre las mujeres, las diferencias de género más acusadas se dan entre las personas de 30 a 44 años: sufren pobreza de tiempo el 52,2\% de las mujeres, frente a un $42,7 \%$ de los hombres.

- Desde la perspectiva de ocupación laboral, las personas ocupadas a tiempo completo y las que conviven con dependientes son las más afectadas por la pobreza de tiempo. Considerando el indicador relativo de pobreza de tiempo, que resulta en un $25,8 \%$ para el conjunto de la población de 16 y más años, quienes trabajan a jornada completa $(45,3 \%)$ y quienes conviven dentro del hogar con personas dependientes (44,5\%) presentan una incidencia significativamente mayor de este fenómeno.

- Por último, si se analiza la relación entre la pobreza monetaria y la pobreza de tiempo, cabe destacar que las personas que sufren pobreza de tiempo tienen menores tasas de pobreza monetaria que las personas que disponen de mayor tiempo libre. Sin embargo, ciertos grupos -como por ejemplo, las personas mayores- aparecen bien protegidos frente a ambos riesgos, mientras que otros - las personas de nacionalidad extranjera, las que conviven con personas dependientes, las personas menores de 44 años y las mujeres en general- tienen un mayor riesgo de padecer ambas situaciones. En todo caso, sólo entre las personas de nacionalidad extranjera el riesgo de padecer ambos tipos de pobreza se acerca al $10 \%$. 


\section{Bibliografía referenciada}

BURCHARDT, T. (2008): Time and Income Poverty, serie CASE Reports, $n-57$, Londres, Centre for Analysis of Social Exclusions, págs. 1-101 [rhttp://sticerd. Ise.ac.uk/dps/case/cr/CASEreport57.pdf〉].

EUSTAT (2006): Encuesta de Presupuestos de Tiempo 2003, serie Monográficos, Vitoria-Gasteiz, Euskal Estatistika Erakundea-Instituto Vasco de Estadística [<http://www.eustat. eus/elementos/ele0004000/ti_encuestade-presupuestos-de-tiempo-2003monograficosbrbrlip-dirltr-stylemargin-left2opx-margin-right-opxpresentacion-indiceintroduccionp/info004095_c.pdf>].

- (2003): Encuesta de Presupuestos de Tiempo. Análisis de resultados, Vitoria-Gasteiz, Euskal Estatistika Erakundea-Instituto Vasco de Estadística [«http://www.eustat.eus/elementos/ eleo003200/ti_encuesta-de-presupuestosde-tiempo-2003-analisis-de-resultados/ infooo3219_c.pdf>].
GAMMAGE, S. (2009): Género, pobreza de tiempo y capacidades en Guatemala: un análisis multifactorial desde una perspectiva económica, CEPAL Naciones Unidas, sede subregional de México [<http://hdl.handle. net/11362/25902>].

SIIS CENTRO DE DOCUMENTACIÓN Y ESTUDIOS (2015a): “LOS usos del tiempo de la ciudadanía guipuzcoana y su relación con la pobreza, 2014" [inédito].

- (2015b): $2^{a}$ Encuesta de Pobreza y Exclusión Social de Gipuzkoa / Gipuzkoako Pobrezia eta Gizarte Bazterketari buruzko 2. Inkesta, Donostia-San Sebastián, Diputación Foral de Gipuzkoa [khttp://behagi.eus/files/informes/ ii.epesg.2014.pdf〉]..

STATISTICS SWEDEN (s.d.): Harmonised European Time Use Survey ('https://www.h5.scb.se/tus/tus/〉). 